\title{
Flood risk assessment of river "Kelani Ganga" exceeding its threshold water level
}

\author{
Charith Dushyantha ${ }^{1, *}$, and Irina Ptuhina ${ }^{1}$ \\ ${ }^{1}$ Peter the Great St. Petersburg Polytechnic University, St. Petersburg, Russian Federation
}

\begin{abstract}
Flood risk assessment curves were developed for a flood risk assessment carried out in Colombo, Sri Lanka. Annual maximum water levels at three gauging stations in Kelani Ganga were used as data to prepare the flood risk assessment. Information sources include the Ministry of Disaster Management, Irrigation department and Department of Metrology. Current approaches to risk assessment function development were improved by using the extreme value theory. The most suitable model from the extreme value theory was defined by the behaviour of the probabilistic density function. The probability of a threshold water level exceeding in a given year can be predicted by using the developed model. According to the results of the flood risk assessment at the three gauging stations along river Kelani Ganga, the Hanwella station is at an $89.3 \%$ high risk of inundating the area with the water level reaching up to $9.6 \mathrm{~m}$ in 10 years of time. These results can be used to develop hazard maps for these areas as one of the criteria that must be taken into consideration when choosing the optimal site for construction.
\end{abstract}

\section{Introduction}

Floods are the most destructive form of natural hazards in both local and global contexts. This is true in terms of both loss of life and property damage. It is also the most prevalent form of natural hazard. No country in the world, except the most arid, can be thought as entirely free from flooding. In certain regions flooding is more prevalent than others. Asian continent is found to be one of the most flood affected regions in the world. Sri Lanka is also among them. Having floods is more common than any natural hazard in Sri Lanka. Floods are natural events, which occur frequently in urban areas such as Colombo, Kalutara, Mathara and Galle and will continue in the future due to the ongoing development of the country. Although people have taken some actions and have been prepared to minimize the flood risk in urban areas, the risk of the area being inundated is still there due to heavy rains of monsoons.

Colombo District is one of the most vulnerable districts in Sri Lanka according to the statistics provided by the Ministry of disaster management. That is because the river "Kelani Ganga" flows through Colombo district. Due to heavy rains, the river overflows and inundates most of the district causing damages to economy of that area [1-3]. The Japan International Cooperation Agency has reported in their data collection survey on

\footnotetext{
*Corresponding author: wa.charith@gmail.com
} 
disaster reduction section in Sri Lanka, that river "Kelani Ganga" flooded Nagalagam Street by exceeding its threshold water level by 22 times from 1962 to 2016, Hanwella by exceeding its threshold water level by 33 times from 1978 to 2016 and Glencourse by exceeding its threshold water level by 33 times from 1960 to 2016. During the 2016 flood event, 228817 affected people, seven deaths and one missing person were reported [4]. Thus, it is necessary to control and minimize these damages and develop a safe environment for the society.

Flood risk and its damages can be reduced by flood protection and management such as, (a) modifying susceptibility to flood damage (actions taken before flood), (b) modifying flood waters, and (c) modifying impact of flooding (during and after flood) [5].

Flood protection measures can be categorized as structural (hard) and non-structural (soft). Structural defences are all about building dams and dikes. These measures have been used since ancient times. Building of reservoirs, where excess water due to heavy rains can be stored, allows to control distribution of stream flow and helps to reduce the flood problem by flood peaks. Flood risk predicting and warning are very important components when it comes to minimizing flood risk. Non-structural flood protection measures are used for this. Flood predicting is based on mathematical modelling, where specialists use data from annual rainfall to predict the flow of a river (discharge volume, maximum water level and inundated area). It reduces flood damage by allowing the public to act before the stage increases to a threshold level.

A study of Damage curves for Colombo District in Sri Lanka was reported by Priyani Dias in 2017. In that study, depth vs. damage curves were plotted for building fabrics, building contents of distributed infrastructures and vehicles [6].

The same researcher discussed the Qualitative flood risk assessment for the western province in Sri Lanka in a separate paper in 2017. A model was developed using flow accumulation, rainfall intensity, geology, land use, slope, elevation and distance from drainage network. An economic vulnerability map, social flood risk and economic flood risk maps were developed for the Western Province in that study [7]. But these papers were mainly focused on damages that a flood event may carry along with it when it appears.

The aims of this paper are:

1. To develop a mathematical model by analysing the varying water level of river Kelani Ganga at three gauging stations Nagalagam, Hanwella and Glencourse;

2. To calculate the risk of the water level exceeding the threshold level at these three stations in 5 and 10 years using the above mentioned model.

\section{Methods}

This paper is based on the extreme value theory which is a branch of statistics dealing with the extreme deviations from the median of probability distributions.

The classical theory of extreme values mainly deals with the properties of the maximum distribution [8-14].

Theorem 1

Consider $M_{n}=\max \left(\xi_{1}, \xi_{2}, \ldots \xi_{n}\right)$ where $\xi_{i}$ - independent and identically distributed random variables. $M_{n}$ - The maximum of the first $n$. If for some constants $a_{n}>0, b_{n}$ :

$$
P\left[a_{n}\left(M_{n}-b_{n}\right) \geq x\right] \stackrel{w}{\longrightarrow} G(x)
$$

Then the nondegenerate distribution function $G(x)$ takes one of the three extreme value forms mentioned below: 


$$
\begin{aligned}
& \text { Type 1: } G(x)=\exp \left(-e^{-x}\right),-\infty<x<\infty, \\
& \text { Type 2: } G(x)=\left\{\begin{array}{l}
0, x \leq 0, \\
\exp \left(-x^{-\alpha}\right), \alpha>0, x>0,
\end{array}\right. \\
& \text { Type 3: } G(x)=\left\{\begin{array}{l}
\exp \left[-(-x)^{a}\right], \alpha>0, x \leq 0, \\
1, x>0
\end{array}\right.
\end{aligned}
$$

The theorem 2 mentioned below allows us to determine the type of nondegenerate distribution function $G(x)$ which can be chosen among the three types when each random variable $\xi_{n}$ has a given distribution function $F(x)$ which belongs to the domain of attraction ( for maxima ) of $G$.

Theorem 2. Consider that the distribution function $F(x)$ of independent and identically distributed random variables formed by the sequence $\xi_{n}$ is absolutely continuous and has the density $f$. Then the following conditions are considered to be sufficient enough for the distribution function $F(x)$ to belong to the corresponding domain of attraction.

Type 1: if $f$ has a negative derivative $f^{\prime}$ for every $x$ in some interval $\left(x_{0}, x_{F}\right)$

$$
x_{F} \leq \infty, f(x)=0 \text { for every } x \geq x_{F} \text { and } \lim _{t \rightarrow x_{F}} \frac{f^{\prime}(t)[1-F(t)]}{f^{2}(t)}=-1
$$

Type 2: $f(x)>0$ for every finite set $x \geq x_{0}$ and $\lim _{t \rightarrow \infty} \frac{t f(t)}{1-F(t)}=\alpha>0$

Type 3: $f(x)>0$ for every $x$ on some finite set interval $\left(x_{0}, x_{F}\right)$,

$$
f(x)=0 \text { for every } x>x_{F} \text { and } \lim _{t \rightarrow x_{F}} \frac{\left(x_{F}-t\right) f(t)}{1-F(t)}=\alpha>0
$$

Theorem 3. Constants $a_{n}, b_{n}$, in the convergence $P\left[a_{n}\left(M_{n}-b_{n}\right) \geq x\right] \stackrel{w}{\longrightarrow} G(x)$ in each of the above mentioned cases can be found as follows:

$$
\begin{gathered}
\text { Type 1: } a_{n}=\left[g\left(\gamma_{n}\right)\right]^{-1}, b_{n}=\gamma_{n} \\
\text { Where } \gamma_{n}=F^{-1}(1-1 / n), g(t)=\int_{t}^{x_{F}} \frac{1-F(u)}{1-F(t)} d u \text { for } t<x_{F} \\
\text { Type 2: } a_{n}=\gamma_{n}^{-1}, b_{n}=0 \\
\text { Type 3: } a_{n}=\left(x_{F}-\gamma_{n}\right)^{-1}, b_{n}=x_{F}
\end{gathered}
$$

\section{Results}

Let $H_{1}, H_{2}, \ldots H_{T}$ be the water level during flood events in $1^{\text {st }}, 2^{\text {nd }}, . ., \mathrm{n}^{\text {th }}$ years respectively. Then the flood risk assessment of water level $H$ exceeding the threshold level $h$ in a time period of $T$ years can be written as: 


$$
R_{T}(H>h)=P\left(\mathrm{M}_{T}>h\right), \text { where } M_{T}=\max \left(H_{1}, H_{2}, \ldots H_{T}\right) .
$$

This problem can be solved as a distribution function of random variables $H_{i}$. Where $H_{i}$ - water levels during flood events.

The distribution function of random variables can be written as [16, 17]:

$$
F(h)=\left\{\begin{array}{l}
1-e^{-\lambda(h-k)}, h \geq k \\
0, h<k
\end{array}\right.
$$

Where $\lambda$ - rate parameter, $k$ - water level

Corollary 1.

The case of the exponential distribution $F(h)$ belonging to the domain of attraction of type 1 .

Proof:

In an exponential distribution, the probabilistic density function is written as:

$$
\begin{gathered}
f(h)=\left\{\begin{array}{l}
\lambda e^{-\lambda(h-k)}, h \geq k \\
0, h<k
\end{array}\right. \\
f^{\prime}(h)=-\lambda^{2} e^{-\lambda(h-k)}<0, h \geq k
\end{gathered}
$$

The function $f$ has a negative derivative $f^{\prime}$ for every $h$ in the interval $(k, \infty)$ and satisfies the condition given in formula (5). Therefore $F(H)$ belongs to the domain of attraction of Type 1 .

Corollary 2.

Based on corollary 1. $F(h)$ belongs to the domain of attraction of Type 1. Furthermore, $a_{n}, b_{n}$ can be found using formula (11) and theorem 3 :

$$
\begin{gathered}
a_{T}=\lambda \\
b_{T}=\frac{\ln T}{\lambda}+k
\end{gathered}
$$

The flood risk assessment of water level $H$ exceeding the threshold level $h$ in the period of $T$ years can be written as:

$$
\begin{gathered}
R_{T}(H>h)=P\left(M_{T}>h\right)=1-P\left(M_{T} \leq h\right)=1-P\left[a_{T}\left(M_{T}-b_{T}\right) \leq a_{T}\left(h-b_{T}\right)\right] \\
\stackrel{w}{\longrightarrow} 1-G\left[a_{T}\left(h-b_{T}\right)\right]= \\
1-\exp \left[-e^{-a_{T}\left(h-b_{T}\right)}\right]= \\
=1-\exp \left\{-e^{-\lambda\left[h-\left(\frac{\ln T}{\lambda}+k\right)\right]}\right\}=1-\exp \left(-e^{-\lambda h+\ln T+\lambda k}\right)= \\
=1-\exp \left(-T \cdot e^{\lambda k} \cdot e^{-\lambda h}\right)
\end{gathered}
$$

Thus,

$$
\begin{gathered}
R_{T}(H>h)=1-\exp \left(-T \cdot A \cdot e^{-\lambda h}\right) \\
A=e^{\lambda k}
\end{gathered}
$$


Consider the situation where random variables $H_{i}$ have the function distribution:

$$
F(h)=\exp \left(-e^{-\lambda^{\prime}(h-l)}\right) \text { - extreme value distribution (type I). }
$$

Each extreme value distribution belongs to its own domain of attraction and the constants $a_{n}, b_{n}$ can be determined as:

$$
\begin{gathered}
a_{T}=\lambda^{\prime} \\
b_{T}=\frac{\ln T}{\lambda^{\prime}}+l
\end{gathered}
$$

In the case where $H_{i}$ is distributed according to the extreme value distribution (type I), the risk assessment of water level $H$ exceeding threshold level $h$ in a period of $T$ years is also written as:

$$
\begin{gathered}
R_{T}(H>h)=1-\exp \left(-T \cdot A \cdot e^{-\lambda^{\prime} h}\right) \\
A=e^{\lambda^{\prime} l}
\end{gathered}
$$

Using the above theorems, mathematical models were developed to calculate the risk at each of the three stations.

With the help of the derived mathematical models and data collected from the relevant ministries, below mentioned distribution functions were plotted for the three stations:

- empirical distribution function

- exponential distribution $F(h)=\left\{\begin{array}{l}\left.1-e^{-\lambda(h-k)}\right) \\ 0, h<k\end{array}, h \geq k\right.$

- $\quad$ extreme value distribution (type I) $F(h)=\exp \left(-e^{-\lambda^{\prime}(h-l)}\right)$

The Empirical and model distribution functions of water level $H$ at Nagalagam, Hanwella and Glencourse are shown in Figures 1,2 and 3 respectively. Rate parameters and threshold water levels of the three gauging stations are shown in table 1.

Table 1. Rate parameters and water levels of three gauging stations.

\begin{tabular}{|c|c|c|c|}
\hline & Nagalagam & Hanwella & Glencourse \\
\hline $\begin{array}{c}\text { exponential } \\
\text { distribution }\end{array}$ & $\lambda=0.8107, \mathrm{k}=4.8$ & $\lambda=1.4751, \mathrm{k}=8.4$ & $\lambda=0.9469, \mathrm{k}=17.1$ \\
\hline $\begin{array}{c}\text { extreme value } \\
\text { distribution } \\
\text { (type I) }\end{array}$ & $\lambda^{\prime}=0.8294, l=5$ & $\lambda^{\prime}=1.4993, l=8.6$ & $\lambda^{\prime}=0.9475, l=17.3$ \\
\hline
\end{tabular}




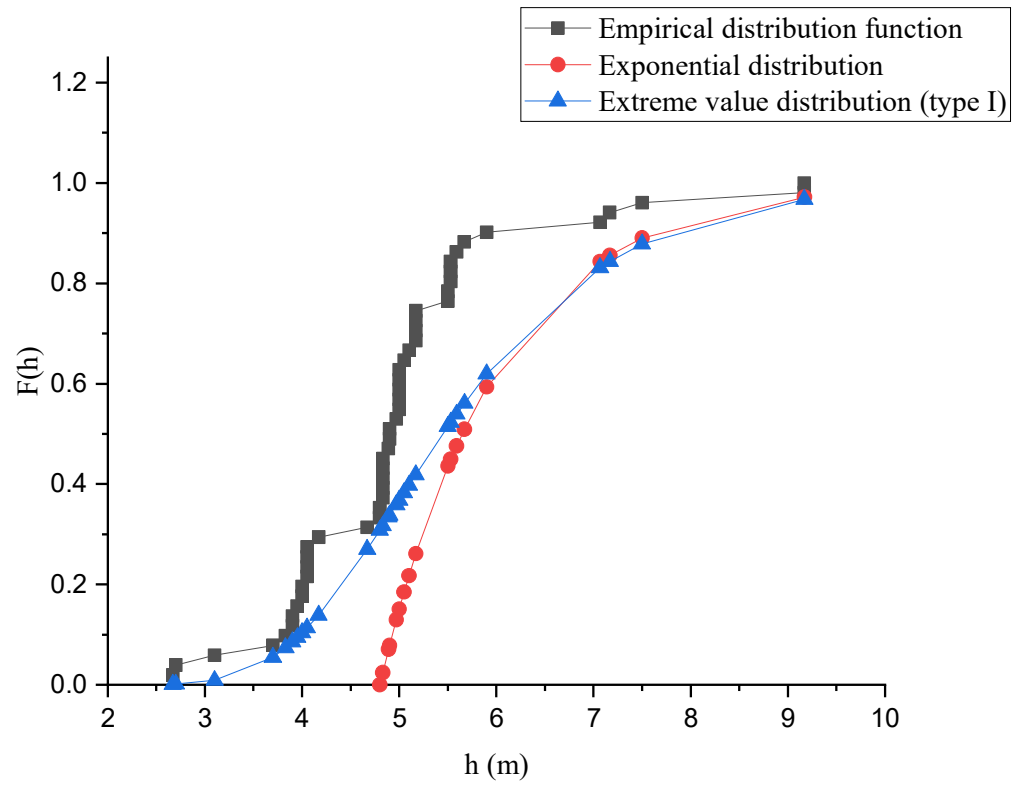

Fig. 1. Empirical and model distribution functions of water level $H$ at Nagalagam.

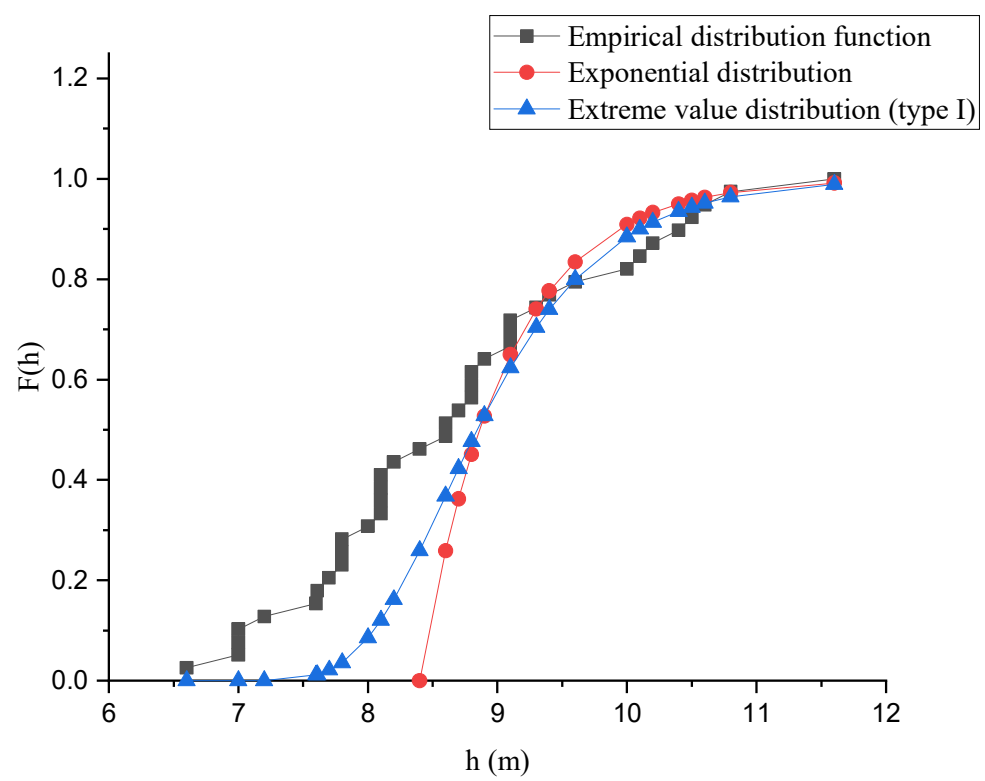

Fig. 2. Empirical and model distribution functions of water level $H$ at Hanwella. 


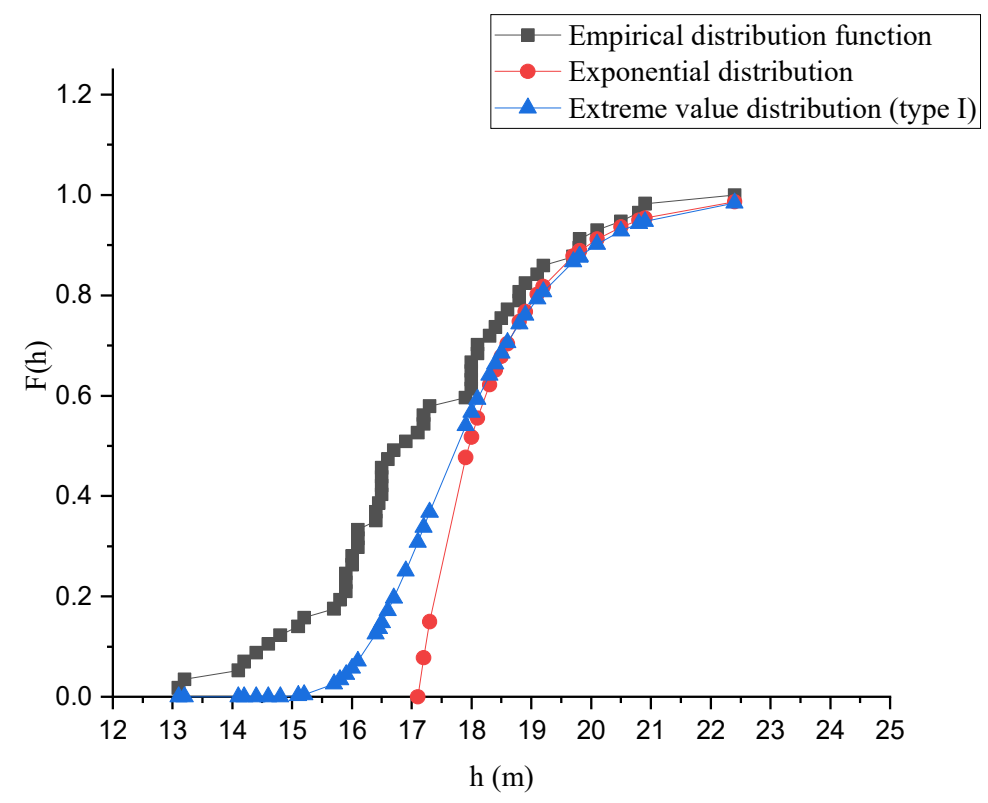

Fig. 3. Empirical and model distribution functions of water level $H$ at Glencourse.

To calculate the risk of some water level $H$ exceeding the threshold water level $h$ in $T$ years, the following formulas were used:

$$
\begin{aligned}
& R_{T}(H>h)=1-\exp \left(-T \cdot e^{\lambda k} \cdot e^{-\lambda h}\right) \\
& R_{T}(H>h)=1-\exp \left(-T \cdot e^{\lambda^{\prime} l} \cdot e^{-\lambda^{\prime} h}\right)
\end{aligned}
$$

Risk assessment of the water level exceeding the threshold level at Nagalagam station in 5, 10 and 51 years, at Hanwella station in 5, 10 and 39 years and Glencourse station in 5, 10 and 57 years are shown in figure 4,5 and 6 below. 


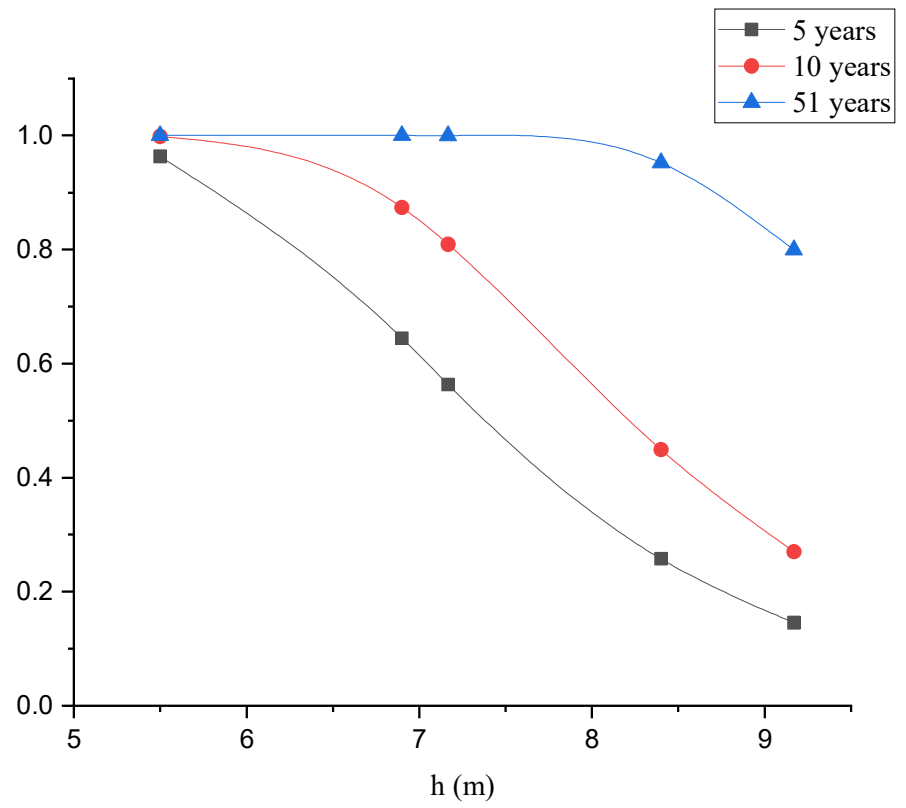

Fig. 4. Risk assessment of the water level exceeding the threshold level at Nagalagam station in 5, 10 and 51 years.

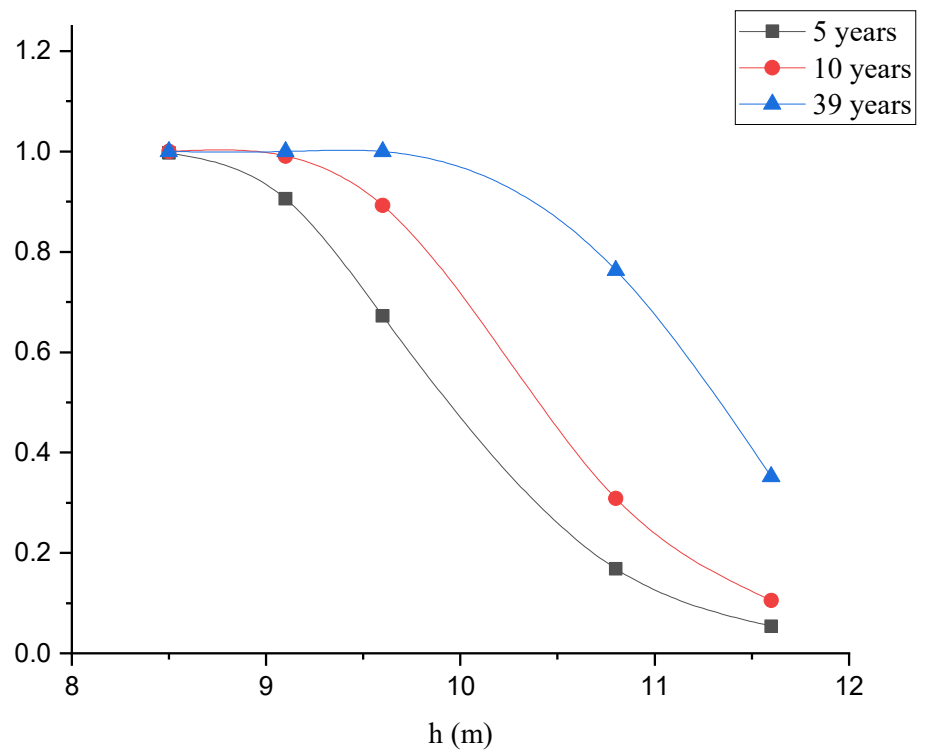

Fig. 5. Risk assessment of the water level exceeding the threshold level at Hanwella station in 5, 10 and 39 years. 


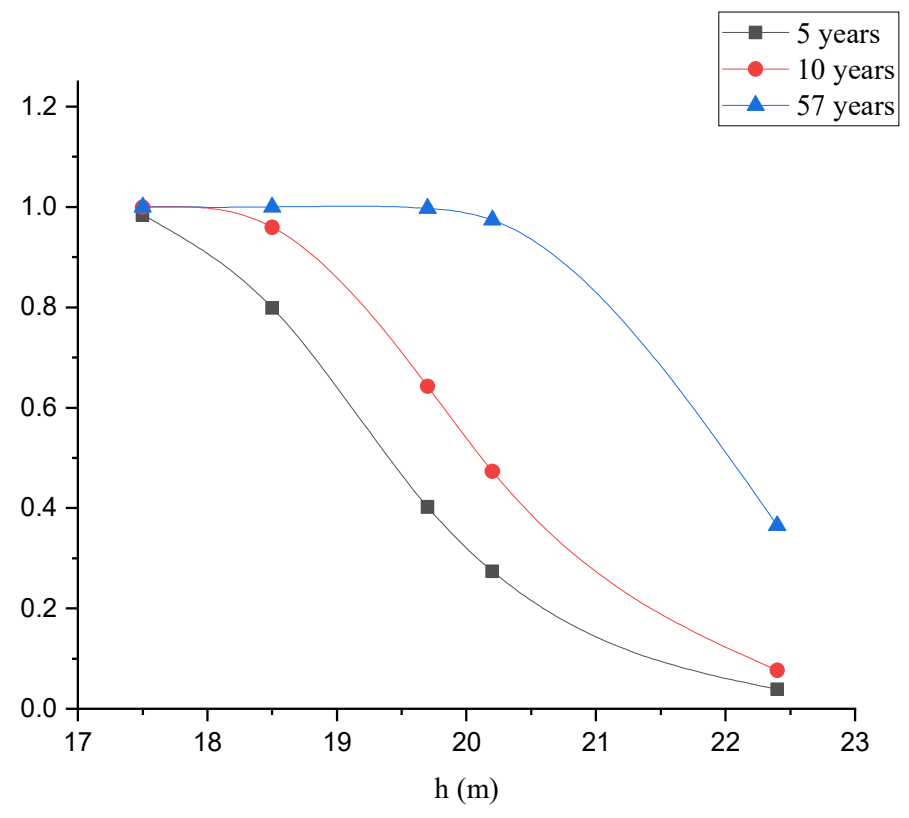

Fig. 6. Risk assessment of the water level exceeding the threshold level at Glencourse station in 5, 10 and 57 years.

\section{Discussion}

The following results were obtained by this research:

1. A mathematical model was developed to calculate the water level of river Kelani Ganga exceeding the threshold level at three different gauging stations for any given year.

2. Using the derived graphs, probability of the water level exceeding the threshold level for specific time periods were calculated.

Models for risk assessment of water level of river Kelani Ganga exceeding the threshold level were developed by using data about the annual water level at the three gauging stations Nagalagam, Hanwella and Glencourse.

It is evident that risk assessments of the water level exceeding the threshold level in the shorter periods of time of five and ten years are most crucial for the responsible authorities to take necessary measures in order to minimize flood vulnerability in the relevant areas.

The risk of water level at Nagalagam station exceeding the threshold level and reaching $7.12 \mathrm{~m}$ in 5 and 10 years are 0.563 and 0.809 respectively. The risk of the water level at Hanwella station exceeding the threshold level $8.6 \mathrm{~m}$ and reaching a level of $9.6 \mathrm{~m}$ in 5 and 10 years are 0.673 and 0.893 respectively, while the risk of the water level at Glencourse station reaching a level of $19.7 \mathrm{~m}$ in 5 and 10 years are 0.402 and 0.643 respectively. Among these three stations, the Hanwella station is at $89.3 \%$ risk of being inundated with the water level rising up to $19.7 \mathrm{~m}$ in 10 years of time.

The Japan International Cooperation Agency has also stated in their assessment that the areas around the Nagalagam and Hanwella gauging stations are at high risk of being inundated due to heavy rainfalls.

Establishing gauging stations as much as possible to measure the water level annually along the river Kelani Ganga is required to monitor and forecast flood risk as it is one of the most populated areas where most administrative businesses are situated. Other flood 
vulnerable areas of Sri Lanka where major rivers flow will also need to follow up the same process to asses flood risk.

\section{Conclusion}

Hanwella gauging station is the station with the highest risk of being inundated and consequently, the most crucial area for relevant authorities to take necessary measures to control flood damages. It is at an $89.3 \%$ risk of being inundated with the water level rising up to $19.7 \mathrm{~m}$ in 10 years.

These results can be used to develop hazard maps for the relevant areas as one of the criteria that must be taken into consideration when choosing the optimal site for construction. The main advantage of having these hazard maps is that people with less technical knowledge can easily understand the flood vulnerability of that area and contribute to minimizing flood damages.

\section{References}

1. Sri Lanka Post-Disaster Needs Assessment - May 2016, Ministry of Policies and Economic Affairs and Ministry of Disaster Management, https://www.lk.undp.org/content/srilanka/en/home/library/environment energy/publica tion4.html

2. Sri Lanka Post-Disaster Needs Assessment - May 2017, Ministry of Policies and Economic Affairs and Ministry of Disaster Management, https://www.lk.undp.org/content/srilanka/en/home/library/environment_energy/SriLan ka-Rapid-Post-Disaster-Needs-Assessment-2017.html

3. Hazard Profiles in Sri Lanka, Ministry of Disaster Management, http://www.disastermin.gov.lk/web/index.php?option=com content\&view=category\&l ayout $=$ blog\&id $=73 \&$ Itemid $=70 \&$ lang $=$ en

4. Data Collection Survey on Disaster Risk Reduction Sector in Sri Lanka, Japan International Cooperation Agency (JICA), Colombo, August (2017) http://open jicareport.jica.go.jp/pdf/12111894.pdf

5. K.D.W. Nandalal, Use of a hydrodynamic model to forecast floods of Kalu River in Sri Lanka (2008) DOI: 10.1111/j.1753-318X.2009.01032.X

6. P. Dias, N.M.S.I. Arambepola, K. Weerasinghe, K.D.N. Weerasinghe, Development of damage function for flood risk assessment in the city of Colombo (Sri Lanka) (2017) DOI: 10.1016/j.proeng.2018.01.043

7. K.M. Weerasinghe, H. Gehrels, N.M.S.I. Arambepola, H.P. Vajja, J.M.K. Herath, K.B. Atapattu, Qualitative flood risk assessment for the western province of Sri Lanka. (2017) DOI: 10.1016/j.proeng.2018.01.065

8. E. S. Wentzel, Probability Theory. 576 (1956)

9. Y. Galambos, Asymptotic theory of extreme order statistics 304 (1984).

10. E.J. Gumbel, Statistics of extremes 449 (1965).

11. A.N. Kolmogorov, Probability Theory and Mathematical Statistics 535 (1986)

12. Leadbetter, M.R., Lindgren, G. and Rootzén, H., Extremes and related properties of random sequences and processes (Springer Science \& Business Media, 2012).

13. M. V. Rodkin, Earthquakes and other types of disasters: typical distribution theories and processes of disaster development, thesis abstract 44. (2004) 
14. L. Z. Rumshinsky, Elements of Probability Theory 254, (1970)

15. E.S. Wentzel, Probability Theory. 576 (1959)

16. M. V. Rodkin, Model for developing a synergistic effect in severe disaster. (2005)

17. Feller V. An Introduction to Probability Theory and Its Applications, Volume 2. 528 (1984) 